\title{
Comparison of acid-induced inflammatory responses in the rat lung during high frequency oscillatory and conventional mechanical ventilation
}

Ming-Yuan Jian, Tomonobu Koizumi, Toshiki Yokoyama, Kenji Tsushima, Keishi Kubo.

The First Department of Internal Medicine,

Shinshu University School of Medicine, Matsumoto, Japan

Short title: HFOV and acid-aspiration lung injury

Address for correspondence and reprints requests: Tomonobu Koizumi, M.D., First Department of Internal Medicine, Shinshu University School of Medicine 3-1-1 Asahi Matsumoto, 390-8621, Japan

Phone: +81-263-37-2631, Fax: +81-263-36-3722

E-mail: tomonobu@shinshu-u.ac.jp

Word counts: 2697 words

\begin{abstract}
Background: The present study was performed to compare the effects of high frequency oscillatory ventilation (HFOV) with conventional mechanical ventilation (CMV) on pulmonary inflammatory responses in a rat acid-induced lung injury model.
\end{abstract}

Methods: Anesthetized rats were instilled intratracheally with $\mathrm{HCl}(0.1 \mathrm{~N}, 2 \mathrm{~mL} / \mathrm{kg})$ and then randomly divided into three mechanical ventilation settings: HFOV (an oscillatory frequency 
of $15 \mathrm{~Hz}$, mean airway pressure (MAP) of $9 \mathrm{cmH}_{2} \mathrm{O}$ ), CMV at tidal volume of $12 \mathrm{~mL} / \mathrm{kg}$ and $6 \mathrm{~mL} / \mathrm{kg}$ for $5 \mathrm{~h}$.

Results: After $\mathrm{HCl}$ instillation, HFOV significantly attenuated the increases in neutrophil infiltration and TNF- $\alpha$ concentration in bronchoalveolar lavage fluid compared with the CMV groups. During HFOV, there was an inhibition of an increase in TNF- $\alpha$ mRNA expression and a decrease in SP-A mRNA expression induced by acid instillation.

Conclusion: This animal study demonstrates that HFOV is a suitable form of mechanical ventilation to prevent inflammatory responses in acid-induced lung injury.

Key words: mechanical ventilation, lung injury, surfactant, low tidal volume,

ARDS, TNF- $\alpha$, ventilation-induced lung injury 


\section{Introduction}

Mechanical ventilation is the main treatment strategy for patients with acute respiratory distress syndrome (ARDS). However, conventional ventilation strategies are associated with further pulmonary damage and inflammation during the management of patients and experimental models with ARDS [1-4]. In particular, the large tidal volume (VT) and high peak airway pressure contribute to ventilation-induced lung injury $[5,6]$.

Various lung protection strategies have been developed to minimize lung injury, such as low-VT conventional mechanical ventilation and high frequency oscillatory ventilation (HFOV). Previous studies showed that low-VT ventilation reduced production of tumor necrosis factor (TNF)- $\alpha$ in the lung, attenuated lung injury, and improved oxygenation compared with high-VT ventilation $[4,7,8]$. Furthermore, low-VT ventilation also improved survival and reduced the inflammatory response in patients with ARDS [9].

HFOV is a form of mechanical ventilation that uses a small VT than dead space. HFOV could expand the lung with a continuous distending pressure and produce a superimposed pressure oscillation at high frequency. Theoretically, HFOV prevents high peak alveolar pressures and maintains a fixed airway pressure, both of which prevent overdistension [10-12]. HFOV has been shown to reduce the incidence of lung inflammation and improve oxygenation in various experimental models [13-16]. In a surfactant-deficient rabbit lung injury model, animals in the HFO group had lower neutrophil counts and lower levels of platelet activating factor and thromboxane $\mathrm{B}_{2}$ in bronchoalveolar lavage fluid (BALF) compared with those on conventional mechanical ventilation (CMV) [13]. In a rabbit lung injury model induced by $N$-nitroso- $N$-methyl urethane (NNMU), HFOV 
resulted in superior oxygenation compared with the VT $10 \mathrm{~mL} / \mathrm{kg}$ ventilation group [14]. Thus, the beneficial effects of HFOV have been observed in certain types of lung injury, but little is known about its application in direct lung injury. Acid aspiration is a major cause of ARDS and acute lung injury leading to direct lung damage and acute inflammation [17], and has been used as an experimental model of ARDS due to aspiration pneumonia $[17,18]$. It was reported that $15 \mathrm{~mL} / \mathrm{kg}$ VT of CMV had a protective effect for acid-induced lung injury compared with $30 \mathrm{ml} / \mathrm{kg}$ [5], but there is little information at the further lower VT of CMV on inflammatory responses to acid instillation.

Thus, the present study was performed to evaluate the effects of HFOV on acid-induced lung injury in rats. In addition, the impacts were compared with those of CMV using lower and standard VT, especially focusing on pulmonary inflammatory responses including the TNF- $\alpha$ and surfactant system after acid instillation.

\section{Methods}

\section{Materials and animals}

The study protocol was approved by the Institutional Review Board for Animal Experimentation of Shinshu University. Care and handling of animals were performed in accordance with the guidelines of the National Institutes of Health.

Animal preparation; Six-week-old male Sprague-Dawley rats weighing $200-250$ g were purchased from Japan SLC Inc. (Hamamatsu, Japan). Each rat was anesthetized intraperitoneally with pentobarbital sodium $(40 \mathrm{mg} / \mathrm{kg})$. A right jugular venous line was prepared for fluid maintenance with normal saline (NS) at $1 \mathrm{~mL} / \mathrm{h}$. A tracheotomy was performed and animals were ventilated mechanically by a CMV with $10 \mathrm{~mL}$ of VT 
(respirator model SN-480-7; Shinano, Tokyo, Japan). An uncuffed and iron containing endotracheal tube (1.5 $\mathrm{mm}$ interior diameter) was used in the present study. Hydrochloric acid $(0.1 \mathrm{~N}, 2 \mathrm{~mL} / \mathrm{kg})$ was instilled into the trachea after attaining a stable baseline and then randomly divided into three mechanical ventilation settings.

\section{Mechanical ventilation setting}

The CMV ventilator was set at a VT of $12 \mathrm{~mL} / \mathrm{kg}$ (HCl-VT 12 group, $n=16$ ) or $6 \mathrm{~mL} / \mathrm{kg}$ (HCl-VT 6 group, $n=16$ ), with a fixed respiratory rate $(\mathrm{RR})$ of 60 breaths/min, a fraction of inspired oxygen $\left(\mathrm{FiO}_{2}\right)$ of 1.0 , and a positive end-expiratory pressure of $1 \mathrm{cmH}_{2} \mathrm{O}$. For the HCl-HFOV group $(n=16)$, we used a newly developed HFOV (R100; Metran Co. Ltd., Saitama, Japan) for adults and infants in the present study. This machine has a rotary-valve type and can regulate a wide range oscillatory frequency $(5-15 \mathrm{~Hz})$ and generate approximately $100 \mathrm{ml}$ of $\mathrm{Vt}$ at $15 \mathrm{~Hz}$ in cases of adults. The HFOV in the present study was used at an oscillatory frequency of $15 \mathrm{~Hz}$, mean airway pressure (MAP) of $9 \mathrm{cmH}_{2} \mathrm{O}$, and $\mathrm{FiO}_{2}$ of 1.0. Mechanical ventilation in CMV or HFOV was continued for $5 \mathrm{~h}$ after acid instillation.

In addition, the study included two control groups (NS-VT 12 group and NS-HFOV group) of rats that were instilled intratracheally with $2 \mathrm{~mL} / \mathrm{kg}$ of NS and then ventilated with CMV (VT $12 \mathrm{~mL} / \mathrm{kg}, n=16)$ and rats ventilated with HFOV $(n=16)$, for $5 \mathrm{~h}$. Airway pressures during CMV before and after acid instillation were recorded using a water-filled manometer attached to an endotracheal tube. 


\section{Study protocol}

In the present study, the following two experiments were performed separately. Experiment 1; this experiment was performed to measure blood gas analysis and collect bronchoalveolar lavage. A cannula was inserted into the right carotid artery to take blood samples for gas analysis. $5 \mathrm{~h}$ after the instillation of the $\mathrm{HCl}$ or normal saline, animals were sacrificed and bronchoalveolar lavage was performed to collect bronchoalveolar lavage fluid (BALF). Experiment 2: $5 \mathrm{~h}$ after $\mathrm{HCl}$ or normal saline instillation, lung tissue samples were isolated to evaluate the histopathological changes and assess wet to dry weight ratios.

$B A L F$; After $5 \mathrm{~h}$ of ventilation, the lungs were lavaged with $5 \mathrm{~mL}$ of $\mathrm{NS}$ four times (total 20 $\mathrm{mL})$ and collected ( $n=8$ for each group).

Histopathology and measurement of lung wet/dry weight ratio; Lung tissue samples were obtained to quantify mRNA of TNF- $\alpha$ and surfactant (SP)-A. In addition, the tissue samples were also used to evaluate histopathological changes and to assess pulmonary edema by determination of the lung wet-to-dry weight ratio (W/D) ( $n=8$ for each group).

\section{Measurements}

Arterial blood gases; Blood samples for measurement of partial oxygen $\left(\mathrm{PO}_{2}\right)$ and carbonate tension $\left(\mathrm{PaCO}_{2}\right)$ were taken from the arterial catheter at baseline, 2.5 and $5 \mathrm{~h}$ after $\mathrm{HCl}$ or $\mathrm{NS}$ instillation (model 178; Corning, Medfield, MA).

BALF; Cell counts were determined using a hemocytometer (Sysmex F-520; Sysmex, Kobe, Japan). Neutrophil differential counts were determined in 200 cells in smears stained with May-Giemsa. The optical density at $412 \mathrm{~nm}\left(\mathrm{OD}_{412}\right)$ was measured to determine pulmonary hemorrhage using a Double Beam Spectrophotometer (UVIDEC-610A; Japan Spectroscopic 
Co., Tokyo, Japan). Albumin and TNF- $\alpha$ concentrations in BALF were determined by nephelometric immunoassay and enzyme-linked immunosorbent assay (ELISA, Immunoassay kit; TFB Co., Tokyo, Japan), respectively.

Real-time quantitative RT-PCR of TNF- $\alpha$ and SP-A; To synthesize cDNA, aliquots of $1 \mu \mathrm{g}$ of total RNA extracted from lung tissue were reverse transcribed (GeneAmp RNA PCR kit components; Applied Biosystems, Foster City, CA) with TNF- $\alpha$ or SP-A primers, using the protocol recommended by the manufacturer. Real-time PCR was performed on a Light Cycler $^{\mathrm{TM}}$ instrument (Roche, Mannheim, Germany). The PCR primers were synthesized according to published sequences of glyceraldehyde-3-phosphate dehydrogenase (GAPDH), TNF- $\alpha$ and SP-A (GenBank accession numbers: AF106860, NM012675, and M15754, respectively).

\section{Statistical analysis}

All data are expressed as means \pm SEM. Differences between groups were evaluated by analysis of variance (ANOVA) followed by Bonferroni's test, and $P<0.05$ was taken to indicate significance. All tests were performed using Stat View 5.0 software (Abacus Concepts, Berkeley, CA). 


\section{Results}

A total of 85 rats were initially included in the present study. Five died before sample collection (1 in HCl-VT 12 group, 2 in HCl-VT 6 group, and 2 in HCl-HFOV group). Mean airway pressures (MAP) before and after acid instillation in control and CMV groups are shown in Table 1. There were no significant differences among groups and time courses after acid instillation.

\section{Changes in arterial blood gases (Fig. 1)}

Intratracheal instillation of $\mathrm{HCl}$ resulted in deterioration of oxygenation and a marked fall in the $\mathrm{PaO}_{2} / \mathrm{FiO}_{2}(\mathrm{P} / \mathrm{F})$ ratio (Fig.1 A). The $\mathrm{P} / \mathrm{F}$ ratio was significantly higher at the end of the experiment in the HCl-HFOV group compared with HCl-VT 12 and HCl-VT 6 groups. At 2.5 and $5 \mathrm{~h}$ after acid administration, severe hypercapnia was noted in HCl-VT 6 compared with baseline and the other two groups (Fig.1 B). Rats in the HCl-VT 12 group also showed a significant increase in $\mathrm{PaCO}_{2}$ at the end of the experiment. HFOV did not cause significant changes in $\mathrm{PaCO}_{2}$ during the experiment. There were no significant changes in $\mathrm{P} / \mathrm{F}$ ratio and $\mathrm{PaCO}_{2}$ in NS-VT 12 group and NS-HFOV group during the experimental period.

\section{Changes in BALF parameters (Figs. 2, 3)}

The recovery rates of BALF were greater than $90 \%$ in all groups and there were no significant differences in recovery rate among the groups. Total numbers of nuclear cells and neutrophils in BALF of the HCl-VT 12 group were significantly higher than those in the normal control group (Fig. 2 A,B). The increased cells in the HCl-VT 12 group consisted mainly of neutrophils. HFOV and low-VT treatment significantly decreased the HCl-induced 
increase in nucleated cells and neutrophil infiltration in the lungs. Pulmonary hemorrhage, concentrations of albumin, and TNF- $\alpha$ concentrations in BALF are shown in Fig. 3. The $\mathrm{OD}_{412}$ in the HCl-VT 12 group was significantly higher than those in the other groups, suggesting marked hemorrhage in lung tissues of these rats. HFOV and HCL-VT 6 ventilation significantly reduced the pulmonary hemorrhage induced by $\mathrm{HCl}$ instillation compared with HCL-VT 12 ventilation. Albumin and TNF- $\alpha$ concentrations in BALF were significantly higher in $\mathrm{HCl}$-instilled rats than in normal controls. HFOV and HCL-VT 6, but not VT 12 ventilation, significantly attenuated the pulmonary vascular permeability (albumin concentration). Only HFOV resulted in a significant reduction of TNF- $\alpha$ production in BALF (Fig.3,C).

\section{Changes in lung wet-to-dry weight ratio (Fig. 4)}

The W/D ratio in rats treated with $\mathrm{HCl}$ was significantly increased compared with normal controls. HFOV and low-VT ventilation significant decreased the W/D ratio compared with HCL-VT 12 treatment.

\section{Changes in TNF- $\alpha$ and SP-A mRNA levels (Fig. 5)}

$\mathrm{HCl}$ instillation significantly increased the levels of TNF- $\alpha$ mRNA in the lung. Low-VT ventilation appeared to attenuate this increase, but the difference was not significant. The TNF- $\alpha$ /GAPDH ratio in the HCl-HFOV group was the lowest among HCl-instilled rats. $\mathrm{HCl}$ instillation significantly decreased SP-A mRNA level in the lung. Low-VT ventilation did not affect the decreased SP-A mRNA level. The SP-A/GAPDH ratio in the HCl-HFOV group was the highest among $\mathrm{HCl}$-instilled rats. 


\section{Histological changes (Fig. 6)}

Histological examination of the lung revealed thickening and damage of the alveolar wall in HCl-treated rats. These findings were attenuated in HCl-HFOV rats. Furthermore, HFOV reduced the infiltration of neutrophils and accumulation of erythrocytes in the alveolar spaces. Hyaline membrane formation was also detected in the HCl-VT 12 group but not in the HCl-HFOV group. 


\section{Discussion}

In the rat acid-induced lung injury model, HFOV improved oxygenation and attenuated lung injury by minimizing increases in TNF- $\alpha$ production and neutrophil infiltration in BALF compared with those ventilated with moderate conventional VT ventilation. HFOV also modulated the decrease in SP-A mRNA expression induced by acid instillation. In addition, CMV at low VT for $5 \mathrm{~h}$ resulted in a progressive increase in $\mathrm{PaCO}_{2}$, while $\mathrm{HFOV}$ resulted in no alterations in $\mathrm{PaCO}_{2}$ during the experimental period.

Many studies have suggested the importance of ventilator settings, such as VT, in acid-induced lung injury models. In a canine model, ventilation using VT of $30 \mathrm{~mL} / \mathrm{kg}$ caused greater pulmonary edema than VT of $15 \mathrm{~mL} / \mathrm{kg}$ [5]. In contrast, ventilation using VT of $6 \mathrm{~mL} / \mathrm{kg}$ attenuated IL-6 and vascular endothelial growth factor receptor expression in the lungs of mice following acid instillation into the airways compared with VT of $17 \mathrm{~mL} / \mathrm{kg}$ [7]. Our results indicated that ventilation using VT of $6 \mathrm{~mL} / \mathrm{kg}$ attenuated neutrophil infiltration, albumin concentrations and lung edema. Thus, low-VT ventilation provides some protective effects in acid-induced lung injury. However, such ventilatory support failed to reduce TNF- $\alpha$ production both in BALF and in lung tissue in the present study. Likewise, in a lung lavaged rabbit model, ventilation using VT of $6 \mathrm{~mL} / \mathrm{kg}$ had no beneficial effects on TNF- $\alpha$ increase compared with VT of $10 \mathrm{~mL} / \mathrm{kg}$ [16]. In the present study, only HFOV treatment significantly attenuated the increase in TNF- $\alpha$ at both protein and gene levels. Thus, HFOV showed superior effects in the reduction of inflammatory responses to acid instillation compared with CMV using various VT settings. 
However, there may be limitations to interpretation of the results in the present study. It remains unclear whether this setting of HFOV was optimal for protection against acid-induced lung injury and/or suitable for comparing the inflammatory responses with those in CMV. In addition, we selected $1 \mathrm{cmH}_{2} \mathrm{O}$ of PEEP, which might be relatively low compared with those in other animal experiments $[13,14,16]$. The other CMV settings including various VT setting might be more reasonable for open lung strategy, compared with those in CMV used in the present study. However, it has been recommended that the initial setting of MAP to obtain better oxygenation during HFOV should be slightly higher than that during CMV [10-13] or adjusted to a 1.5-fold lower inflection point on the pressure-volume curve if possible [19]. Thus, we adjusted the MAP at $9 \mathrm{cmH}_{2} \mathrm{O}$ in the present study based simply on the MAP during CMV at $6 \mathrm{~mL} / \mathrm{kg}$ of VT (Table 1). Our results suggested that the less inflammatory response to acid-induced lung injury during HFOV could be due to superior of HFOV compared with CMV, but other ventilatory strategies in both CMV and HFOV might influence our studies. In our previous study, we showed that HFOV with a relatively high MAP setting applied by a proper pressure - volume curve has a superior preventive effect on oleic acid-induced acute lung injury compared with standard MAP settings of HFOV [15]. Thus, further studies are required using various MAP settings monitored by a static inspiratory pressure-volume curve of the respiratory system in large animal models.

Ventilation of normal lungs with large VT results in depletion of the surfactant and development of pulmonary edema [20]. Similarly, cell stretching is important for surfactant production in the injured lung [21]. Surfactant protein is mainly produced by type II alveolar 
epithelial cells and can be classified into SP-A, -B, -C, and -D types [22]. SP-A is thought to be a good biomarker of lung injury [23]. A decrease in the level of SP-A mRNA expression corresponds to that of the SP-A protein level and could be a marker for inhibition of secretion [23]. We observed a decrease in SP-A gene expression in the rat acid-induced lung injury model, suggesting epithelial cell damage. SP-A expression was higher in the HFOV group than in the moderate and low-VT ventilated groups. Another study showed a 50\% decrease of SP-C expression after ventilation with either VT of 12 or $6 \mathrm{~mL} / \mathrm{kg}$ than in uninjured, unventilated rats in an acid-induced lung injury model [24]. The deterioration of alveolar surfactant large aggregate formation was minimized by HFOV compared with CMV (TV, 10 $\mathrm{mL} / \mathrm{kg}$ ) in a rabbit acute lung injury model [14]. Furthermore, intratracheal administration of TNF- $\alpha$ decreased the mRNA expression levels of SP-A, $-\mathrm{B}$, and $-\mathrm{C}$ both in vivo and in vitro [25-27]. In contrast, SP-A inhibited BALF TNF- $\alpha$ production following intratracheal administration of LPS in SP-A gene-targeted mice [28]. Taken together, these observations indicated that in CMV a reduction of functional surfactant may be responsible, at least in part, for the increased levels of cytokines in BALF. In the present study, surfactant protein was preserved during HFOV, which was associated with a milder inflammatory response and better oxygenation compared with CMV.

In the present study, ventilation using VT of $6 \mathrm{~mL} / \mathrm{kg}$ was associated with severe respiratory acidosis. Lower $\mathrm{PaO}_{2}$ and higher $\mathrm{PaCO}_{2}$ levels were also observed in NNMU-induced rabbit lung injury during ventilation with VT of $6 \mathrm{~mL} / \mathrm{kg}$ compared with HFOV (VT 6 mL/kg vs. HFOV; $\mathrm{PaO}_{2} 100$ vs. 350 mmHg; $\mathrm{PaCO}_{2} 90$ vs. 40 mmHg; $P<$ 0.05)[15]. Furthermore, rabbits ventilated using VT of $6 \mathrm{~mL} / \mathrm{kg}$ died at various time points 
during the experimental period [16]. The severity of hypercapnia was approximately similar to that recorded in the present study. In patients with ARDS, low VT is also accompanied by significantly higher $\mathrm{PaCO}_{2}$ levels and respiratory acidosis from the first hour to day 7 compared with moderate VT [9]. Thus, based on our results, HFOV provided better oxygenation and had protective effects on lung injury without any hypercapnia.

In conclusion, the results of the present study indicated that mechanical ventilation alters inflammatory responses to acid instillation in rat lungs. Compared with CMV, HFOV provides greater lung protection and less inflammation, while maintaining normal oxygenation and acid-base parameters. HFOV is as safe as CMV ventilation in lung injury and should be considered as an option for lung protection in terms of reduced inflammation. 


\section{References}

1. Chiumello D, Pristine G, Slutsky AS. Mechanical ventilation affects local and systemic cytokines in an animal model of acute respiratory distress syndrome. Am J Respir Crit Care Med. 1999;160:109-16.

2. Takata M, Abe J, Tanaka H, Kitano Y, Doi S, Kohsaka T, Miyasaka K. Intra-alveolar expression of tumor necrosis factor-alpha gene during conventional and high-frequency ventilation. Am J Respir Crit Care Med. 1997;156:272-9.

3. Matsuoka T, Kawano T, Miyasaka K. Role of high-frequency ventilation in surfactant-depleted lung injury as measured by granulocytes. J Appl Physiol. 1994;76:539-44.

4. Tremblay L, Valenza F, Ribeiro SP, Li J, Slutsky AS. Injurious ventilatory strategies increase cytokines and c-fos m-RNA expression in an isolated rat lung model. J Clin Invest. 1997;99:944-52.

5. Corbridge TC, Wood LD, Crawford GP, Chudoba MJ, Yanos J, Sznajder JI. Adverse effects of large tidal volume and low PEEP in canine acid aspiration. Am Rev Respir Dis. $1990 ; 142: 311-5$.

6. Dreyfuss D, Soler P, Basset G, Saumon G. High inflation pressure pulmonary edema: respective effects of high airway pressure, high tidal volume, and positive end-expiratory pressure. Am Rev Respir Dis. 1988;137:1159-64. 
7. Gurkan OU, O'Donnell C, Brower R, Ruckdeschel E, Becker PM. Differential effects of mechanical ventilatory strategy on lung injury and systemic organ inflammation in mice. Am J Physiol Lung Cell Mol Physiol. 2003;285:L710-8.

8. Savel RH, Yao EC, Gropper MA. Protective effects of low tidal volume ventilation in a rabbit model of Pseudomonas aeruginosa-induced acute lung injury. Crit Care Med. 2001;29:392-8.

9. Ranieri VM, Suter PM, Tortorella C, De Tullio R, Dayer JM, Brienza A, et al. Effect of mechanical ventilation on inflammatory mediators in patients with acute respiratory distress syndrome: a randomized controlled trial. JAMA. 1999;282:54-61.

10. Krishnan JA, Brower RG. High-frequency ventilation for acute lung injury and ARDS. Chest. 2000;118:795-807.

11. Froese AB. High-frequency oscillatory ventilation for adult respiratory distress syndrome: let's get it right this time. Crit Care Med. 1997;25:906-8.

12. Derdak S. High-frequency oscillatory ventilation for acute respiratory distress syndrome in adult patients. Crit Care Med. 2003;31:S317-23.

13. Imai Y, Kawano T, Miyasaka, K, Takata M, Imai T, Okuyama K. Inflammatory chemical mediators during conventional ventilation and during high frequency oscillatory ventilation. Am J Respir Crit Care Med. 1994;150:1550-54.

14. Kerr CL, Veldhuizen RAW, Lewis JF. Effects of high-frequency oscillation on endogenous surfactant in an acute lung injury model. Am J Respir Crit Care Med. 2001;164:237-42.

15. Ono K, Koizumi T, Nakagawa R, Yoshikawa S, Otagiri T. Comparisons of 
different mean airway pressure settings during high-frequency oscillation in inflammatory response to oleic acid-induced lung injury in rabbits. $J$ Inflamm Res 2009;2:21-8.

16. Imai Y, Nakagawa S, Ito Y, Kawano T, Slutsky AS, Miyasaka K. Comparison of lung protection strategies using conventional and high-frequency oscillatory ventilation. $\mathrm{J}$ Appl Physiol. 2001;91:1836-44.

17. Schuster DP.ARDS: clinical lessons from the oleic acid model of acute lung injury. Am J Respir Crit Care Med. 1994 149;245-60.

18. Jian MY, Koizumi T, Tsushima K, Fujimoto K, Kubo K. Effects of granulocyte colony-stimulating factor (G-CSF) and neutrophil elastase inhibitor (ONO-5046) on acid-induced lung injury in rats. Inflammation. $2004 ; 28: 327-36$.

19. Luecke T, Meinhardt JP, Herrmann P, Weisser G, Pelosi P, Quintel M. Setting mean airway pressure during high-frequency oscillatory ventilation according to the static pressure--volume curve in surfactant-deficient lung injury: a computed tomography study. Anesthesiology. 2003;99:1313-22.

20. Veldhuizen RA, Marcou J, Yao LJ, McCaig L, Ito Y, Lewis JF. Alveolar surfactant aggregate conversion in ventilated normal and injured rabbits. Am J Physiol. 1996;270:L152-8.

21. Wirtz HRW, Bobbs LG. Calcium mobilization and exocytosis after one mechanical stretch of lung epithelial cells. Science. 1990;250:1266-69. 
22. Morimoto Y, Ding L, Oyabu T, Kim H, Ogami A, Hirohashi M, et al. Gene expression of surfactant protein-A and thyroid transcription factor-1 in lungs of rats exposed to silicon-carbide whisker in vivo. J Occup Health. 2003;45:307-12.

23. Awasthi S, Coalson JJ, Crouch E, Crouch E, King RJ. Surfactant proteins A and D in premature baboons with chronic lung injury (Bronchopulmonary dysplasia). Evidence for an inhibition of secretion. Am J Respir Crit Care Med. 1999;160:942-9.

24. Frank JA, Gutierrez JA, Jones KD, Allen L, Dobbs L, Matthay MA. Low tidal volume reduces epithelial and endothelial injury in acid-injured rat lungs. Am J Respir Crit Care Med. 2002;165:242-9.

25. Bachurski CJ, Pryhuber GS, Glasser SW, Kelly SE, Whitsett JA. Tumor necrosis factor-alpha inhibits surfactant protein $\mathrm{C}$ gene transcription. $J$ Biol Chem. 1995;270:19402-7.

26. Arias-Diaz J, Vara E, Garcia C, Gomez M, Balibrea JL. Tumour necrosis factor-alpha inhibits synthesis of surfactant by isolated human type II pneunocytes. Eur J Surg. 1993;159:541-9.

27. Pryhuber GS, Bachurski C, Hirsch R, Bacon A, Whitsett JA. Tumor necrosis factor-alpha decrease surfactant protein B mRNA in murine lung. Am J Physiol. 1996;270:L714-21.

28. Borron P, McIntosh JC, Korfhagen TR, Whitsett JA Taylor J, Wright LR. Surfactant-associated protein A inhibits LPS-induced cytokine and nitric oxide production in vivo. Am J Physiol Lung Cell Mol Physiol. 2000;278:L840-7. 
Table 1

Mean airway pressures before and after acid instillation during conventional mechanical ventilation

\begin{tabular}{|c|c|c|c|}
\hline & \multicolumn{3}{|c|}{ Mean airway pressure (cmH $\mathrm{cm}_{2} \mathrm{O}$} \\
\hline & Baseline & $2.5 \mathrm{~h}$ & $5 \mathrm{~h}$ \\
\hline NS-VT $12 \mathrm{~mL} / \mathrm{kg}$ & $7.5 \pm 0.8$ & $7.6 \pm 0.8$ & $7.9 \pm 1.0$ \\
\hline HCL-VT $6 \mathrm{~mL} / \mathrm{kg}$ & $6.3 \pm 1.0$ & $5.9 \pm 0.4$ & $6.5 \pm 0.8$ \\
\hline HCL-VT $12 \mathrm{~mL} / \mathrm{kg}$ & $7.5 \pm 0.6$ & $7.6 \pm 0.4$ & $8.3 \pm 0.9$ \\
\hline
\end{tabular}

Values are means \pm SEM. 


\section{Figure legends}

Figure 1. Serial changes in the $\mathrm{PaO}_{2} / \mathrm{FiO}_{2}(\mathrm{P} / \mathrm{F})$ ratio (A) and $\mathrm{PaCO}_{2}(\mathrm{~B})$ in rats of each group. NS-HFOV group: rats were instilled with normal saline and ventilated with HFOV; NS-VT12 group: rats were instilled with normal saline and ventilated with CMV of VT 12 mL/kg; HCl-VT12 group: rats were instilled with $\mathrm{HCl}$ and ventilated with CMV of VT 12 $\mathrm{mL} / \mathrm{kg}$; HCl-VT6 group: rats were instilled with $\mathrm{HCl}$ and ventilated with $\mathrm{CMV}$ of VT 6 $\mathrm{mL} / \mathrm{kg}$; HCl-HFOV group: rats were instilled with $\mathrm{HCl}$ and ventilated with $\mathrm{HFOV}$. Values are means \pm SEM. ${ }^{*} P<0.05$, compared with baseline. \# $P<0.05$, compared with other groups.

Figure 2. Nuclear cell counts (A) and neutrophil differential counts (B) in BALF of each group. See Figure 1 for group definitions. Values are expressed as means \pm SEM. ${ }^{*} P<0.05$ vs. NS-HFOV and NS-VT12 groups; \# $P<0.05$ vs. HCl-VT12 group.

Figure 3. Absorbance (A), albumin (B), and TNF- $\alpha$ levels (C) in BALF of each group. See Figure 1 for group definitions. Values are expressed as means \pm SEM. ${ }^{*} P<0.05$ vs. NS-HFOV and NS-VT12 groups; \# $P<0.05$ vs. HCl-VT12 group.

Figure 4. Wet-to-dry weight ratio in all groups. See Figure 1 for group definitions. Values are expressed as means \pm SEM. ${ }^{*} P<0.05$ vs. NS-HFOV and NS-VT12 groups; \# $P<0.05$ vs. HCl-VT12 group.

Figure 5. TNF- $\alpha /$ GAPDH (A) and SP-A/GAPDH mRNA levels (B) in the lung. See Figure 1 for group definitions. Values are expressed as means \pm SEM. $* P<0.05$ vs. NS-HFOV groups; $\# P<0.05$ vs. HCl-VT12 group. 
Figure 6. Photomicrographs of lung tissue in each group. A: NS-HFOV group; B: HCl-VT12 group; C: HCl-VT6 group; D: HCl-HFOV group. Magnification $\times 200$. In the HCl-VT12 group, note the congested alveolar walls, alveolar edema, hyaline membranes with alveolar wall disruption, and the presence of numerous neutrophils and red blood cells in the alveolar spaces. In the HCl-HFOV group, note the presence of only a few neutrophils and red blood cells in the air spaces, the lack of alveolar edema and hyaline membranes, and the intact alveolar walls. 